\title{
Membrane Permeability Rates of Vanadium Ions and Their Effects on Temperature Variation in Vanadium Redox Batteries
}

\author{
Liuyue Cao ${ }^{1}$, Anders Kronander ${ }^{1}$, Ao Tang ${ }^{2}$, Da-Wei Wang ${ }^{1}$ and Maria Skyllas-Kazacos ${ }^{1, *}$ \\ 1 School of Chemical Engineering, University of New South Wales, Sydney, NSW 2052, Australia; \\ 1.cao@unsw.edu.au (L.C.); akronander@gmail.com (A.K.); da-wei.wang@unsw.edu.au (D.-W.W.) \\ 2 Institute of Metal Research, Chinese Academy of Sciences, Shenyang 110016, China; a.tang@imr.ac.cn \\ * Correspondence: m.kazacos@unsw.edu.au; Tel.: +61-2-9385-4335
}

Academic Editor: Xiaoliang Wei

Received: 30 October 2016; Accepted: 6 December 2016; Published: 14 December 2016

\begin{abstract}
The inevitable diffusion of vanadium ions across the membrane can cause considerable capacity loss and temperature increase in vanadium redox flow batteries (VRFBs) over long term operation. Reliable experimental data of the permeability rates of vanadium ions are needed for membrane selection and for use in mathematical models to predict long-term behavior. In this paper a number of ion exchange membranes were selected for detailed evaluation using a modified approach to obtain more accurate permeation rates of $\mathrm{V}^{2+}, \mathrm{V}^{3+}, \mathrm{VO}^{2+}$ and $\mathrm{VO}_{2}{ }^{+}$ions. Three commercial ion exchange membranes-FAP450, VB2 and F930-are investigated. The obtained diffusion coefficients are then employed in dynamic models to predict the thermal behavior under specific operating conditions. The simulation results prove that smaller and more balanced permeability rates of $\mathrm{V}^{2+}$ and $\mathrm{VO}_{2}{ }^{+}$ions are more important to avoid large temperature increases in the cell stack during stand-by periods at high states-of-charge with pumps off.
\end{abstract}

Keywords: permeability rates; diffusion; crossover; ion exchange membrane; vanadium redox flow batteries (VRFBs); capacity; side reactions

\section{Introduction}

The ideal ion exchange membrane for redox flow batteries (RFBs) only transfers $\mathrm{H}^{+}$or other non-reacting ions (such as $\mathrm{Na}^{+}, \mathrm{HSO}_{4}{ }^{-}$, etc.) to complete the internal circuit while separating the catholyte and anolyte to avoid capacity loss and self-discharge. However, over long term operation, the ions in the catholyte and anolyte tend to diffuse across the membrane until reaching equal concentrations in both half-cells. The inevitable crossover issue makes vanadium redox flow batteries (VRFBs) stand out, because the deployment of vanadium as a single active element in both half-cells eliminates cross-contamination of the electrolytes and also makes it possible to restore capacity by periodically remixing the two half-cell electrolytes. In contrast, other RFB systems that employ different elements on each side, have to suffer irreversible contamination and capacity loss that is more difficult to manage.

Apart from the differential diffusion of vanadium ions across the membrane, other side reactions can also lead to capacity loss. Gassing reactions including oxygen evolution on the positive electrode and hydrogen evolution on the negative electrode during charging are likely to happen especially at high state of charge (SOC) under high current densities. Any non-synchronous gassing reactions will contribute to an imbalance between the SOC of the catholyte and anolyte, thus reducing cell capacity. Air oxidation of $\mathrm{V}^{2+}$ ions in the negative half-cell solution will also lead to an imbalance in the SOC of the two half-cell solutions, causing loss of capacity that can only be restored by chemical 
or electrochemical rebalancing. Measures of charging the cell within a reasonable SOC range, or by employing constant current followed by constant voltage charging can minimize problems associated with gassing side reactions while the impact of air oxidation can be minimized by reducing the exposed area of anolyte to the air and/or deaerating the negative reservoir.

Nevertheless, the diffusion of vanadium ions across the membrane still remains an important factor in determining cell performance. Self-discharge occurs when the $\mathrm{VO}^{2+}$ and $\mathrm{VO}_{2}{ }^{+}$from the positive electrolyte react with the $\mathrm{V}^{3+}$ and $\mathrm{V}^{2+}$ ions from the negative electrolyte as given by the following reactions:

In the positive cell:

$$
\begin{aligned}
\mathrm{V}^{2+}+2 \mathrm{VO}_{2}^{+}+2 \mathrm{H}^{+} & \rightarrow 3 \mathrm{VO}^{2+}+\mathrm{H}_{2} \mathrm{O} \\
\mathrm{V}^{2+}+\mathrm{VO}^{2+}+2 \mathrm{H}^{+} & \rightarrow 2 \mathrm{~V}^{3+}+\mathrm{H}_{2} \mathrm{O} \\
\mathrm{V}^{3+}+\mathrm{VO}_{2}^{+} & \rightarrow 2 \mathrm{VO}^{2+}
\end{aligned}
$$

In the negative cell:

$$
\begin{gathered}
\mathrm{VO}_{2}^{+}+2 \mathrm{~V}^{2+}+4 \mathrm{H}^{+} \rightarrow 3 \mathrm{~V}^{3+}+2 \mathrm{H}_{2} \mathrm{O} \\
\mathrm{VO}_{2}^{+}+\mathrm{V}^{3+} \rightarrow 2 \mathrm{VO}^{2+} \\
\mathrm{VO}^{2+}+\mathrm{V}^{2+}+2 \mathrm{H}^{+} \rightarrow 2 \mathrm{~V}^{3+}+\mathrm{H}_{2} \mathrm{O}
\end{gathered}
$$

Unequal diffusion rates of vanadium ions across the membrane can cause a disparity between the SOC of the anolyte and catholyte, thereby leading to capacity fade. Moreover, the exothermic self-discharge reactions can lead to elevated temperature within the cell, especially when the pumps are turned off during stand-by periods [1,2]. Although equipped with a built-in cooling system-“"the circulating electrolyte solutions", the possibility of thermal precipitation of concentrated $\mathrm{VO}_{2}{ }^{+}$in the positive half-cell during static or low flow rate situations needs to be avoided.

Most research groups evaluating or developing novel membranes for the VRB have tended to limit their permeation measurements only to the $\mathrm{VO}^{2+}$ species in the discharged positive half-cell solution [3-11] and very few studies have included the diffusion coefficients of the other three vanadium ions [12-15]. A knowledge of accurate and validated permeability rates of all four vanadium ions is however vital when selecting membranes for VRFBs and predicting the electrochemical and thermal behavior of VRFBs under various operating and climatic circumstances by mathematical modelling. To date, complete diffusion coefficient data has only been published for Asahi Selemion CMV [12,13], Tokuyama Soda CMS and CMX [13], Nafion 115 [14], and silica nanocomposite AEM [15] membranes. None of these membranes is currently being used in commercial VRB systems, so their practical value is limited. The aim of this study is thus to evaluate some of the new membranes that are being commercialized for VRB applications so that their performance can be predicted under a wide range of operating conditions.

A second objective of this study is to improve the currently used methodology for measuring membrane diffusion coefficients of vanadium ions in the VRB in order to obtain more reliable data. Experimental techniques used to monitor and interpret the movement of vanadium ions across the membrane in an operating cell as a function of time are subject to a number of interferences that lead to large errors. The process of ion cross over can involve simultaneous diffusion, migration under external electrical field and osmotic convection associated with the different ionic strengths of the solutions in each half-cell [16]. Several theories have been applied to simulate the ion transport in and across the membrane. Fick's law [17] is the governing law for diffusion processes driven by a concentration gradient. This process is dependent on temperature and obeys the Arrhenius equation [18]. Grossmith et al. [12] firstly applied Fick's first law to experimentally measure the diffusion of vanadium ions across a number of membranes using the assumption of one dimensional steady state diffusion. This theory was subsequently used to measure the permeability rate of vanadium ions especially the $\mathrm{VO}^{2+}$ ion by many research groups [3-11,14,15,19-21]. Heintz et al. [22] 
attempted to employ the Maxwell-Stefan theory to include the electrical field as well as the influence of frictional force between ions based on the ion exchange equilibria data. Later they calculated the ion exchange rate of vanadium ions with $\mathrm{H}_{3} \mathrm{O}^{+}$ions in the membrane with the combination of Donnan equilibrium and diffusion experiment but neglected the frictional effects [13]. Compared to Fick's law, such a method is more comprehensive but also complicated for even binary systems and is limited to only low concentrations of vanadium ions. Chen et al. [23] subsequently incorporated the Nernst-Planck equation to determine the permeation of $\mathrm{VO}^{2+}$ and $\mathrm{VO}_{2}{ }^{+}$ion across cation exchange membranes. The membrane was regarded as charged and the diffusion of vanadium ions was attributed to the concentration gradient as well as the potential difference across the membrane. In fact, the obtained Nernst-Plank equation is in the same form of Fick's diffusion equation and the Donnan potential in their experiment (where vanadium ions exchanged only with $\mathrm{H}_{3} \mathrm{O}^{+}$) can be undermined when exchanging with ions of the same charge, which is closer to reality in an operating VRFB.

To apply these theories, the importance of experimental conditions should not be ignored. Typically, a dialysis cell separated by a membrane is used for the diffusion tests. Vanadium and blank solutions are filled in each side of the membrane as the depletion and enrichment components. The permeability rates are then calculated based on the variation in concentration of vanadium ion in the enrichment solution as a function of time. First of all, the measurement should be carried out with fresh membranes and/or samples treated according to the manufacturers' instructions. The operating history may give rise to swelling, fouling and even degradation of the membrane at different levels that vary with time [13,22-26]. For example, the water content inside the membrane will affect the interaction between the vanadium cations and sulfonic acid group in cation exchange membrane such as Nafion, thus leading to adsorption and fouling to various degrees $[23,25,26]$; the strong acidic electrolyte and the strong oxidative $\mathrm{VO}_{2}{ }^{+}$ions might react with the polymers, altering the chemical structure of the original membranes [27]. Secondly, the hydrating shell of vanadium ions and proton are prone to carrying water molecules across the membrane due to the concentration gradient, while differences in ionic strength between the depletion and enrichment solution can give rise to significant water transfer that could interfere with the active ion diffusion processes across the membrane. The blank solutions should thus be carefully selected for each of the different vanadium ions to balance the ionic strength and osmotic pressure. The electrochemical potential difference at the membrane/solution interface can also be minimized by exchanging with ions of the same valence.

Regarding the cell setup, the static dialysis cell [20] tends to form a diffusive layer on either side of the membrane. Consequently, the vanadium concentration near the surface of the membrane will be much lower than that of the bulk solution, giving rise to concentration polarization and adding unnecessary experimental error to the measurement. Mixing the solution with a magnetic bar $[4-6,13,19,21]$ or circulating the solution by pumps $[3,12,14,23]$ can minimize concentration polarization effects and better represent the real scenario. In the latter circumstance, heating of the solutions by the running pumps can cause temperature variations that should be monitored and controlled to ensure accuracy of the experimental data.

Experimental errors can also be introduced by the analytical method used to measure concentration changes as a function of time. Various methods including potentiometric titration [6,14,23], Ultraviolet (UV) -visible spectroscopy [3,5,6,12-14], inductive couple plasma-atomic emission spectroscopy/mass spectroscopy (ICP-AES/MS) $[4,15,19,20]$ and atomic absorption spectroscopy (AAS) [13] can be used to determine the concentration of vanadium ions in the enrichment solution. The former two methods are highly dependent on the oxidation state of vanadium ions while the latter two can be used to analyze the atomic constituents. Since $\mathrm{V}^{2+}$ and diluted $\mathrm{V}^{3+}$ solutions can be easily oxidized by air, ICP-AES/MS and AAS are better choices for ex-situ concentration determination.

In this paper, the permeability rates of the four vanadium ions across the three kinds of commercial ion exchange membranes were determined by a modified diffusion test based on Fick's first law. The dimensional stability and performance of each of the membranes was also determined and the 
experimental diffusion data obtained was incorporated in the dynamic models based on the work of Tang et al. [1,2] to simulate their effects on thermal behavior under specific operating conditions.

\section{Results and Discussion}

\subsection{Stability of Membranes in $\mathrm{VO}_{2}+$ Solution}

Three ion exchange membranes, Fumasep ${ }^{\circledR}$ FAP-450 (FAP450) and Fumasep ${ }^{\circledR}$ F930-rfd (F930) (Fumatech, Bietigheim-Bissingen, Germany) and VB2 (V-Fuel Pty Ltd., Syndey, Australia) were selected for this study. As mentioned before, membranes for the VRFB should be able to endure the strongly acidic solutions and the strong oxidative influence of the $\mathrm{VO}_{2}{ }^{+}$ions in the charged positive half-cell electrolyte. The three membranes were therefore immersed in $1.6 \mathrm{~mol} \cdot \mathrm{L}^{-1} \mathrm{VO}_{2}{ }^{+} / 4.2 \mathrm{~mol} \cdot \mathrm{L}^{-1}$ total sulphate solutions to investigate their long-term stability. Fumasep ${ }^{\circledR}$ FAP-450 is an anion exchange membrane which has been used in commercial VRFBs (Cellcube) produced by Gildemeister (Würzburg, Germany) [28]. Fumasep ${ }^{\circledR}$ F930-rfd is a reinforced sulfonated tetrafluoroethylene based fluoropolymer-copolymer cation exchange membrane, while VB2 is a cast perfluorosulfonic acid (PFSA)-based cation exchange membrane.

The dimensional variations including length, width and thickness as well as weight were measured over a period of more than 800 days and the results are presented in Figure 1a-d, respectively. All the membranes here showed greater variation in both dimensional size and weight in the first stages of the experiment but then remained relatively stable in the later stages. The length and width of the anion exchange membrane FAP450 increased by around $5 \%-7 \%$ while the thickness remained relatively constant. By comparison, the width of the cation exchange membrane F930 shrank by around $6 \%$ while the length increased slightly. Moreover, the thickness was nearly double the initial size at the end of experiment. Such disparity in the dimensional sizes might be associated with the anisotropy of the membrane or the reinforcement.
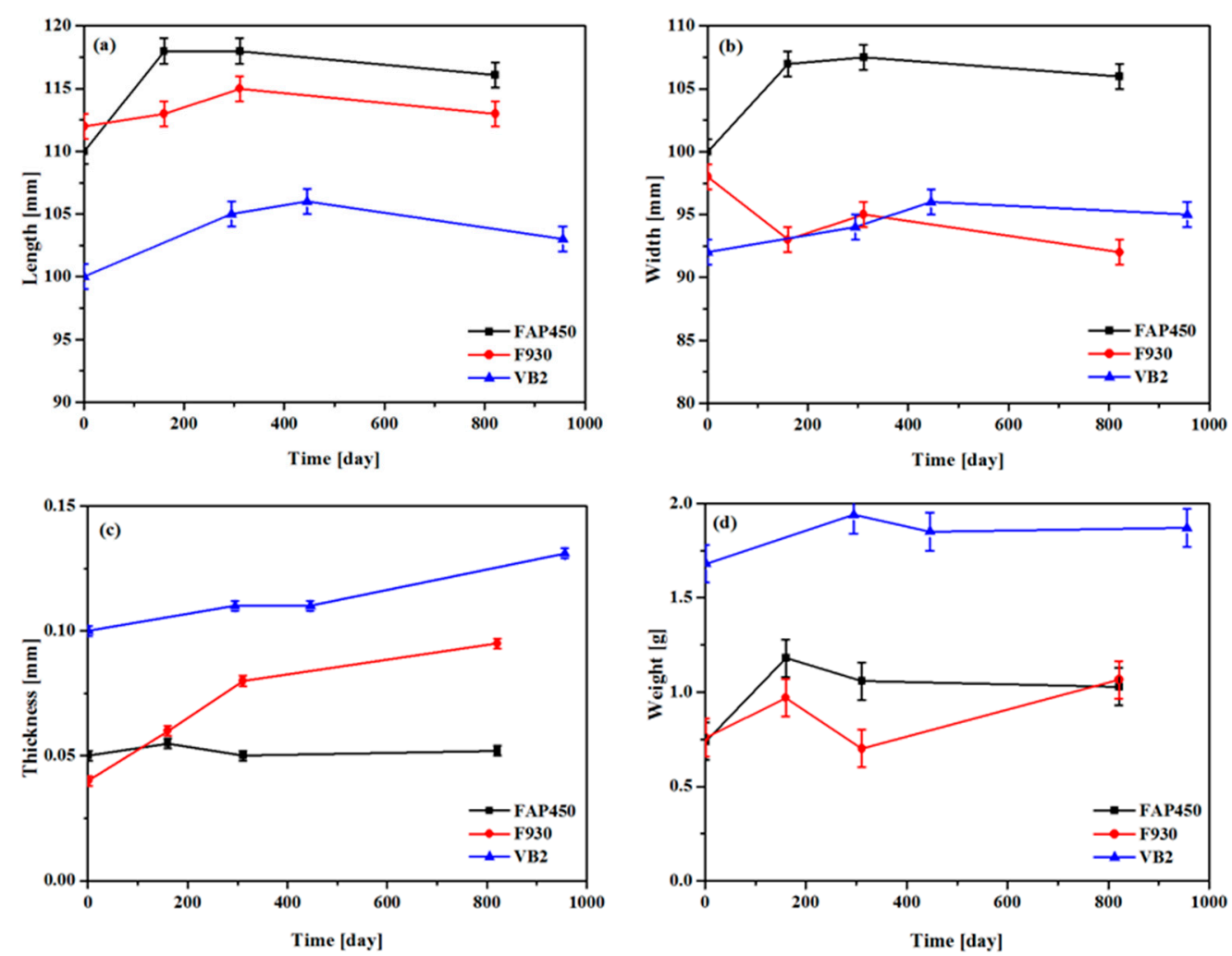

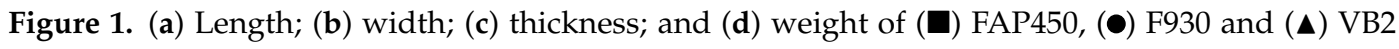
membranes as function of immersing time in $1.6 \mathrm{~mol} \cdot \mathrm{L}^{-1} \mathrm{VO}_{2}+4.2 \mathrm{~mol} \cdot \mathrm{L}^{-1}$ total sulphate solutions. 
VB2 exhibits the best stability among three membranes and all dimensions varied within the range of $3 \%$. In terms of the weight variation, none of the membranes showed any weight loss during the 800 day immersion period, showing excellent long-term stability in the VRB electrolyte. Both FAP450 and F930 showed around 40\% increase in weight while VB2 only increased by $11 \%$ by the end of the study, which indicates that all the membranes had soaked up electrolyte to different extents.

\subsection{Determination of Permeability Rate of Vanadium Ions}

Because of the swelling issues observed in last section, a new piece of dry membrane was employed in each ion permeability rate measurement in order to minimize errors associated with changes in the membrane pore dimensions between experiments. To minimize any errors associated with concentration polarization, the diffusion test cell employed pumps to circulate the solutions continuously. The vanadium ion concentrations at the beginning of the measurement were set as 0 and $1 \mathrm{~mol} \cdot \mathrm{L}^{-1}$ in the enrichment and the depletion side respectively to create considerable concentration difference across the membrane.

In order to minimize osmotic pressure effects, the compositions of the permeating and enrichment solutions for each of the vanadium ions were as follows:

$$
\begin{aligned}
& \mathrm{V}^{2+} \text { ion: } 1 \mathrm{M} \mathrm{VSO}_{4}+1.6 \mathrm{M} \mathrm{H}_{2} \mathrm{SO}_{4} \| 1 \mathrm{M} \mathrm{MgSO}_{4}+1.6 \mathrm{M} \mathrm{H}_{2} \mathrm{SO}_{4} \\
& \mathrm{~V}^{3+} \text { ion: } 0.5 \mathrm{M} \mathrm{V}_{2}\left(\mathrm{SO}_{4}\right)_{3}+1.1 \mathrm{M} \mathrm{H}_{2} \mathrm{SO}_{4} \| 0.5 \mathrm{M} \mathrm{Fe}_{2}\left(\mathrm{SO}_{4}\right)_{3}+1.1 \mathrm{M} \mathrm{H}_{2} \mathrm{SO}_{4} \\
& \mathrm{VO}^{2+} \text { ion: } 1 \mathrm{M} \mathrm{VOSO}_{4}+1.6 \mathrm{M} \mathrm{H}_{2} \mathrm{SO}_{4} \| 1 \mathrm{M} \mathrm{MSO}_{4}+1.6 \mathrm{M} \mathrm{H}_{2} \mathrm{SO}_{4} ; \\
& \mathrm{VO}_{2}{ }^{+} \text {ion: } 0.5 \mathrm{M}\left(\mathrm{VO}_{2}\right)_{2} \mathrm{SO}_{4}+2.1 \mathrm{M} \mathrm{H}_{2} \mathrm{SO}_{4} \| 0.5 \mathrm{M} \mathrm{K}_{2} \mathrm{SO}_{4}+2.1 \mathrm{M} \mathrm{H}_{2} \mathrm{SO}_{4} \text {. }
\end{aligned}
$$

Further experimental details are presented in Section 3.4. The concentration of vanadium ions in the enrichment reservoir and its variation with time was recorded and is presented in Figure 2.
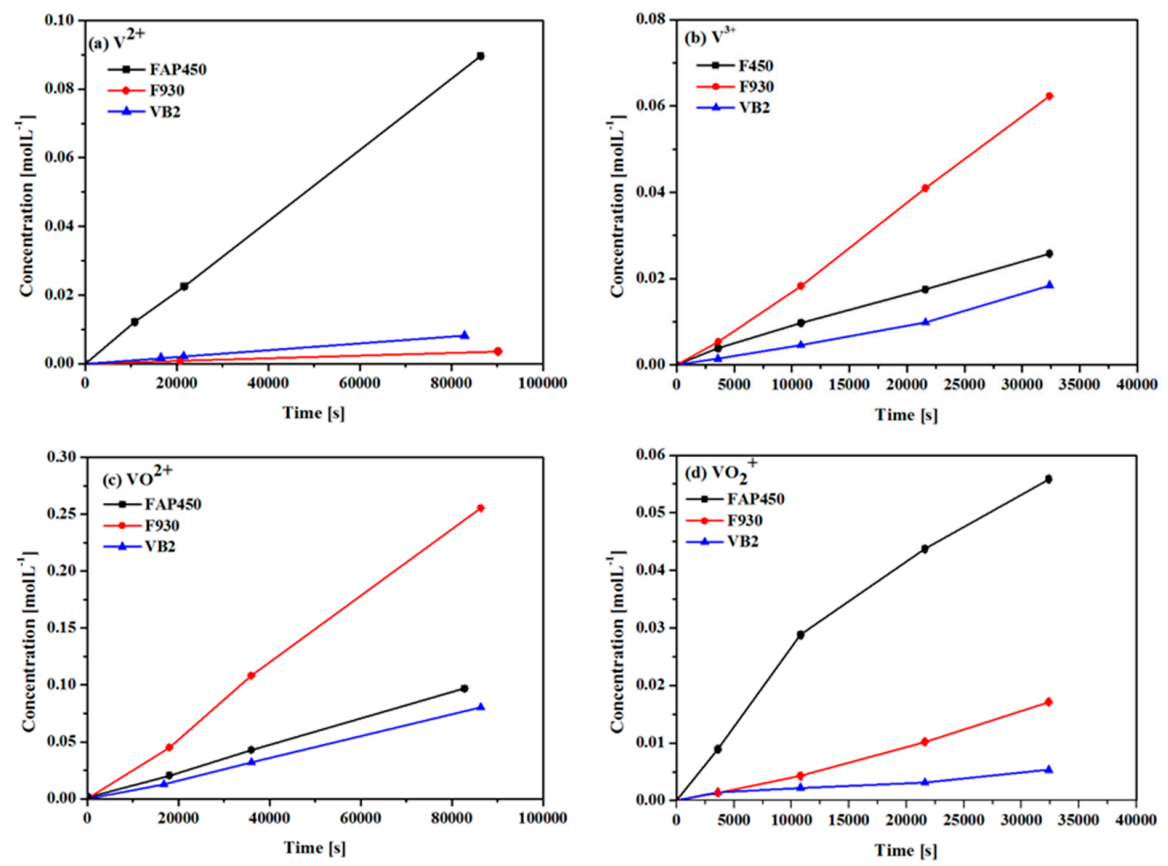

Figure 2. Concentration of vanadium ions: $(\mathbf{a}) \mathrm{V}^{2+} ;(\mathbf{b}) \mathrm{V}^{3+}$; (c) $\mathrm{VO}^{2+}$; and (d) $\mathrm{VO}_{2}{ }^{+}$in the enrichment

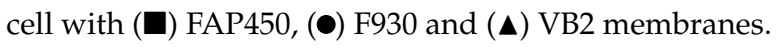

For all systems, the concentrations of transported vanadium ions increase as the diffusion time increases. When the ion permeation commences, vanadium ions migrate across the membrane. The ionic strength balancing ions in the enriching solution simultaneously move in the opposite direction such as (e.g., $\mathrm{Mg}^{2+}$ in $\mathrm{V}^{2+}$ or $\mathrm{VO}^{2+}$ systems, $\mathrm{Fe}^{3+}$ in $\mathrm{V}^{3+}$ system and $\mathrm{K}^{+}$in $\mathrm{VO}_{2}{ }^{+}$system). 
Unlike other reported measurements which only employed $\mathrm{H}^{+}$and $/$or $\mathrm{Mg}^{2+}$ ions as the cations in the blank solutions $[3-6,12-15,19,21,23,29,30]$, here no extra $\mathrm{H}^{+}$ions is needed in the opposite flux to compensate the charge to reach electro-neutrality, which can significantly reduce the coupled water transfer with $\mathrm{H}^{+}$ions (in the hydrous form of $\mathrm{H}_{3} \mathrm{O}^{+}$) and weaken the Donnan potential effect. In fact, no volume change was observed except the volume of taken samples.

However, due to the heat generated by the working pumps and the convection with the varying ambient atmosphere, the temperature of electrolyte fluctuated in the first $3 \mathrm{~h}$, but then remained at $30 \pm 2{ }^{\circ} \mathrm{C}$ afterwards. Therefore, only the concentration values obtained after $180 \mathrm{~min}$ were used for the calculation of permeability rates.

According to the Fick's first law under the assumption of one-dimensional steady state:

$$
J=-k \frac{\left(C_{B}-C_{A}\right)}{L}
$$

where $J$ is the diffusion flux of the amount of vanadium ions per unit area per unit time, $\mathrm{mol} \cdot \mathrm{dm}^{-2} \cdot \mathrm{s}^{-1}$, $k$ is the diffusion coefficient for vanadium ions in the units of $\mathrm{dm}^{2} \cdot \mathrm{s}^{-1}, C_{B}$ and $C_{A}$ are the concentration of vanadium ions contained in vanadium electrolyte and blank solution in the unit of $\mathrm{mol} \cdot \mathrm{L}^{-1}$ respectively, $L$ is the thickness of the membrane in the unit of $\mathrm{dm}, k / L$ is defined as the permeability in $\mathrm{dm} \cdot \mathrm{s}^{-1}$.

The amount of vanadium ions diffused across the membrane per unit time should be equal to the accumulation rate of vanadium ions in the blank solution side:

$$
J \cdot A=V_{A} \frac{d C_{A}}{d t}
$$

where $A$ is the exposed area of the membrane in the unit of $\mathrm{dm}^{2}, V_{A}$ is the volume of the blank solution in the unit of $\mathrm{dm}^{3}$.

$$
V_{A}\left(C_{A}-C_{A 0}\right)=V_{B}\left(C_{B 0}-C_{B}\right)
$$

where $C_{A 0}$ and $C_{B 0}$ are the initial concentration of vanadium ions in the blank solution and vanadium electrolyte respectively.

Hence, the above equations can be combined to give:

$$
\frac{d C_{A}}{d t}=\frac{A k}{V_{A} L}\left[C_{B 0}+\frac{V_{A}}{V_{B}} C_{A 0}-\left(1+\frac{V_{A}}{V_{B}}\right) C_{A}\right]
$$

Since $V_{A}=V_{B}=V, C_{A 0}=0$, the equation can be simplified to:

$$
\frac{d C_{A}}{d t}=\frac{A k}{V L}\left(C_{B 0}+C_{A 0}-2 C_{A}\right)
$$

Integrating gives:

$$
\ln \left(C_{B 0}-2 C_{A}\right)-\ln \left(C_{B 0}\right)=-\frac{2 A k}{V L} t
$$

According to Equation (12), a plot of $\ln \left(C_{B 0}-2 C_{A}\right)$ vs. $t$ should give a straight line with slope equal to $-2 A k /(V L)$. The experimental data were thus plotted in Figure 3 and the diffusion coefficient $k$ and permeability rate $k / L$ were calculated from the slope of the line of best fit.

The diffusion coefficient values are thus converted into permeability rates of vanadium ions here by dividing by the thickness of the membrane and the results are presented in Table 1 . The corresponding published data for Nafion 115 [14] is also included for comparison. It needs to be pointed out however, that this comparison may not be meaningful since the Nafion 115 measurements were obtained under different conditions. In their experiment [14], only $\mathrm{H}_{2} \mathrm{SO}_{4}$ solution was employed as the blank solution for all measurements of four vanadium ions, which can cause water transfer deriving from the imbalanced ionic strength and osmotic pressure. 

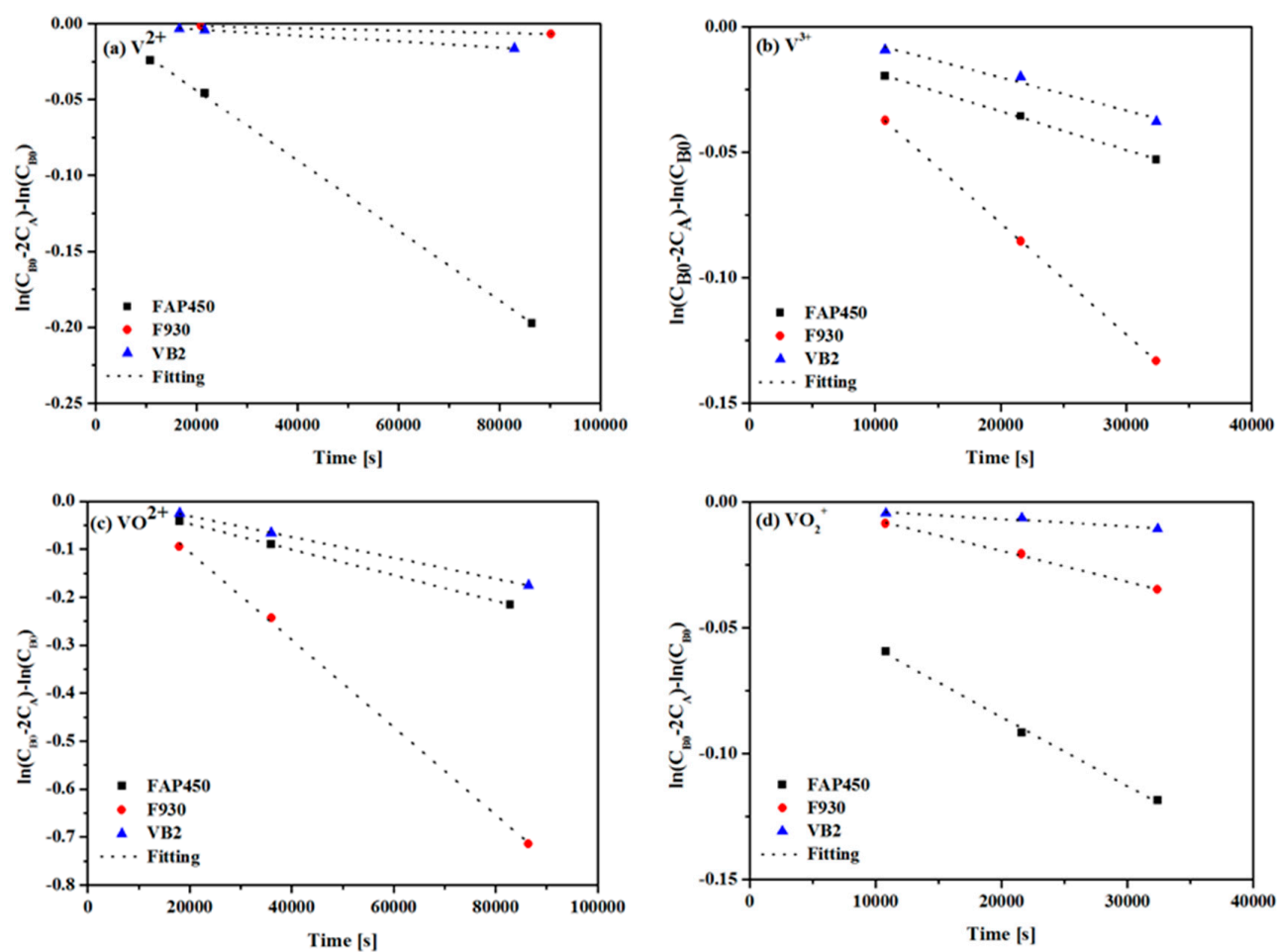

Figure 3. Plot of concentration function vs. time for $(\mathbf{a}) \mathrm{V}^{2+} ;(\mathbf{b}) \mathrm{V}^{3+} ;$ (c) $\mathrm{VO}^{2+}$; and (d) $\mathrm{VO}_{2}{ }^{+}$in the

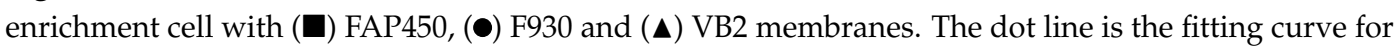
the data obtained after $180 \mathrm{~min}$.

Table 1. Thickness $L(\mu \mathrm{m})$, diffusion coefficients $k\left(\mathrm{dm}^{2} \cdot \mathrm{s}^{-1}\right)$ and permeability rate $k / L\left(\mathrm{dm} \cdot \mathrm{s}^{-1}\right)$ for different vanadium ions across membranes.

\begin{tabular}{|c|c|c|c|c|c|}
\hline Membrane & $L$ & $k\left(\mathrm{~V}^{2+}\right)$ & $k\left(\mathrm{~V}^{3+}\right)$ & $k\left(\mathrm{VO}^{2+}\right)$ & $k\left(\mathrm{VO}_{2}{ }^{+}\right)$ \\
\hline FAP450 ${ }^{1}$ & 50 & $1.61 \times 10^{-10}$ & $1.08 \times 10^{-10}$ & $1.98 \times 10^{-10}$ & $1.92 \times 10^{-10}$ \\
\hline F930 ${ }^{1}$ & 30 & $3.24 \times 10^{-12}$ & $1.86 \times 10^{-10}$ & $3.83 \times 10^{-10}$ & $5.11 \times 10^{-11}$ \\
\hline VB2 ${ }^{1}$ & 100 & $2.76 \times 10^{-11}$ & $1.84 \times 10^{-10}$ & $3.05 \times 10^{-10}$ & $4.03 \times 10^{-11}$ \\
\hline Nafion $115^{2}$ & 127 & $8.76 \times 10^{-10}$ & $3.22 \times 10^{-10}$ & $6.82 \times 10^{-10}$ & $5.89 \times 10^{-10}$ \\
\hline \multicolumn{2}{|c|}{ Membrane } & $k / L\left(\mathrm{~V}^{2+}\right)$ & $k / L\left(\mathrm{~V}^{3+}\right)$ & $k / L\left(\mathrm{VO}^{2+}\right)$ & $k / L\left(\mathrm{VO}_{2}^{+}\right)$ \\
\hline \multicolumn{2}{|c|}{ FAP450 1} & $3.23 \times 10^{-7}$ & $2.16 \times 10^{-7}$ & $3.96 \times 10^{-7}$ & $3.83 \times 10^{-7}$ \\
\hline \multicolumn{2}{|c|}{ F930 ${ }^{1}$} & $1.08 \times 10^{-8}$ & $6.20 \times 10^{-7}$ & $1.28 \times 10^{-6}$ & $1.70 \times 10^{-7}$ \\
\hline \multicolumn{2}{|c|}{ VB2 ${ }^{1}$} & $2.76 \times 10^{-8}$ & $1.84 \times 10^{-7}$ & $3.05 \times 10^{-7}$ & $4.03 \times 10^{-8}$ \\
\hline \multicolumn{2}{|c|}{ Nafion $115^{2}$} & $6.9 \times 10^{-7}$ & $2.54 \times 10^{-7}$ & $5.37 \times 10^{-7}$ & $4.64 \times 10^{-7}$ \\
\hline
\end{tabular}

${ }^{1}$ The values were obtained under $30 \pm 2{ }^{\circ} \mathrm{C}$ in this work; ${ }^{2}$ The values of Nafion 115 are from [14].

It can be found that the results agree quite with the reported data of Nafion 115 [14] in terms of magnitude. Specifically, the permeability rate of different vanadium ions across the anion exchange membrane FAP450 are in the order of $\mathrm{VO}^{2+}>\mathrm{VO}_{2}{ }^{+}>\mathrm{V}^{2+}>\mathrm{V}^{3+}$. Based on Donnan equilibrium theory [31], the positive functional groups of anion exchange membrane have stronger repulsive force against the positive charged vanadium ions with higher valance such as $\mathrm{V}^{3+}$ ion and allow easier passage of lower charged $\mathrm{VO}_{2}{ }^{+}$ion. However, in the meantime, $\mathrm{VO}^{2+}$ can form $\left[\mathrm{VO}\left(\mathrm{H}_{2} \mathrm{O}\right)_{5}\right]^{2+}$ in the moderately acidic media of the vanadium solutions. The hydration shell can lead to accelerated movement of $\mathrm{VO}^{2+}$ ion across the membrane $[23,25,32]$. Another explanation is the known ion pairing between vanadyl and sulphate ions that gives rise to the neutral $\mathrm{VO}-\mathrm{SO}_{4}$ ion pair [33] that is not repelled by the charged fixed groups in the pores of the ion exchange membranes. It is believed that the synergetic effect of Donnan exclusion, hydration and ion pairing causes the different diffusion 
behaviors of four vanadium ions. By comparison, the two cation exchange membranes F930 and VB2 both have much lower diffusivities of $\mathrm{V}^{2+}$ and $\mathrm{VO}_{2}{ }^{+}$, while relatively higher values for $\mathrm{V}^{3+}$ and $\mathrm{VO}^{2+}$. According to Yamamoto [34], the higher-valent positively charged ions have larger affinity for negative functional groups in the cation exchange membrane. Therefore, the high diffusion coefficients of trivalent and divalent vanadium ions are reasonable. Moreover, the hydration and ion pairing of $\mathrm{VO}^{2+}$ ion as discussed above can contribute to higher diffusion coefficient than $\mathrm{V}^{3+}$ ion. That explained why the permeability rates of vanadium ions are in the order of $\mathrm{VO}^{2+}>\mathrm{V}^{3+}>\mathrm{VO}_{2}{ }^{+}>\mathrm{V}^{2+}$ across both F930 and VB2 cation exchange membranes.

Apart from the factors discussed above, different membrane manufacturing methods are also possible to give rise to various diffusion behaviors of vanadium ions. For instance, the extruded PFSA membrane must convert the $\mathrm{SO}_{2} \mathrm{~F}$ to the form of $\mathrm{SO}_{3} \mathrm{~K}$ with $\mathrm{KOH}$ and dimethyl sulfoxide $\left(\left(\mathrm{CH}_{3}\right)_{2} \mathrm{SO}\right)$ solution firstly and need a subsequent acid exchange with $\mathrm{HNO}_{3}$ to achieve the final $\mathrm{SO}_{3} \mathrm{H}$ form. Membrane by extrusion is normally thicker than $125 \mu \mathrm{m}$ [35-37]. The solution casting membrane is prepared by disperse the polymer to the base film as well as a drying process without any extra chemical conversion process. The control of thickness and uniformity is better in solution-casting method compared to the extrusion method [37]. However, to the authors' knowledge, there is no report about detail comparison between the diffusion of vanadium ions across casted and extruded PFSA membranes. More studies on the effect of membrane manufacturing methods on vanadium ions are required.

\subsection{Cycling Test}

Four charge-discharge cycles were carried out in a lab-scale VRFB with electrode area of $25 \mathrm{~cm}^{2}$ and three different membranes within the voltage range of 1.0-1.65 V at constant current of $40 \mathrm{~mA} \cdot \mathrm{cm}^{-2}$. The voltage-time profiles with cycle numbers as well as the cell efficiencies are shown in Figure 4 and Table 2. It can be found that both anion and cation exchange membranes have good and stable performance.

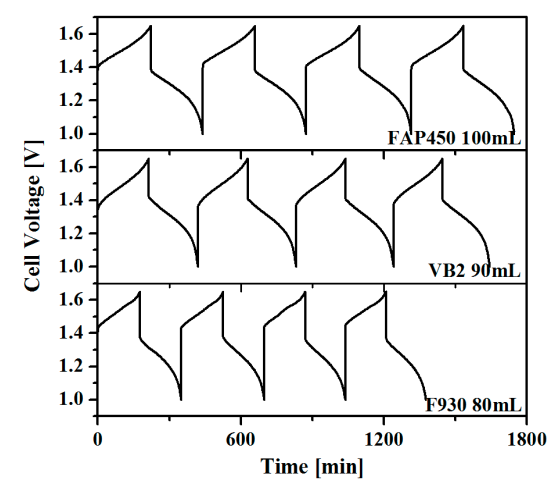

Figure 4. Charge-discharge profiles under constant current charge at $40 \mathrm{~mA} \cdot \mathrm{cm}^{-2}$ for FAP450, VB2 and F930 membranes.

Table 2. Experimental data from cycling test. CE: coulombic efficiency; VE: voltage efficiency; and EE: energy efficiency.

\begin{tabular}{|c|c|c|c|c|c|c|c|}
\hline \multirow{2}{*}{ Membrane } & $C$ & $V$ & $A$ & $L$ & $\mathrm{CE}^{1}$ & $V^{1}{ }^{1}$ & $\mathrm{EE}^{1}$ \\
\hline & $\mathrm{mol} \cdot \mathrm{L}^{-1}$ & $\mathrm{~mL}$ & $\mathrm{~cm}^{2}$ & $\mu \mathrm{m}$ & $\%$ & $\%$ & $\%$ \\
\hline FAP450 & 1.6 & 100 & 25 & 50 & 96.2 & 82.9 & 79.8 \\
\hline VB2 & 1.6 & 90 & 25 & 100 & 97.0 & 85.0 & 82.5 \\
\hline F930 & 1.6 & 80 & 25 & 30 & 97.7 & 81.7 & 79.8 \\
\hline
\end{tabular}

\footnotetext{
${ }^{1}$ The values were obtained from the average efficiencies based on Equations (13)-(15) of four cycles.
} 


\subsection{Thermal Simulation}

To study the effect of permeation on the thermal behaviour of the VRFB, a $40 \mathrm{kWh}$ system was simulated in an residential power arbitrage scenario as described in [1]. Firstly, the cell starts charging during the off-peak period immediately after the discharging during times of peak demand. Once it reaches the upper limited SOC, the VRFB goes into standby mode with pumps off until the battery commences discharging again in the peak period. The permeability rates of three membranes FAP450, VB2 and F930 were employed in the thermal model as well as the published data for Nafion 115 [14] for comparison. All the other parameters are presented in Table 3.

Table 3. Parameters in the thermal simulation. SOC: state of charge.

\begin{tabular}{ccc}
\hline Parameter & Value & Unit \\
\hline Number of cells per stack & 40 & - \\
Vanadium concentration & 2.0 & $\mathrm{~mol} \cdot \mathrm{L}^{-1}$ \\
Capacity & 40 & $\mathrm{kWh}$ \\
Cell resistivity for charge resistance & 2.0 & $\Omega \cdot \mathrm{cm}^{2}$ \\
Cell resistivity for discharge resistance & 2.1 & $\Omega \cdot \mathrm{cm}^{2}$ \\
Minimum air temperature & 10 & ${ }^{\circ} \mathrm{C}$ \\
Maximum air temperature & 30 & ${ }^{\circ} \mathrm{C}$ \\
Discharging period in 24 h format & From $14: 00$ to 20:00 \\
Charge current & 50 & $\mathrm{~A}$ \\
Discharge current & 75 & $\mathrm{~A}$ \\
Lower SOC & 20 & $\%$ \\
Upper SOC & 80 & $\%$ \\
Flow factor for charging & 6 & - \\
Flow factor for dischrging & 6 & - \\
Tank shape & Cylindrical & - \\
Tank material & Polypropylene & - \\
Tank height & 1 & $\mathrm{~m}$ \\
Tank wall thickness & 1 & $\mathrm{~cm}$ \\
Thickness of half-cell cavity & 0.3 & $\mathrm{~cm}$ \\
Length of half-cell cavity (parallel to the flow) & 30 & $\mathrm{~cm}$ \\
Width of half-cell cavity (vertical to the flow) & 50 & $\mathrm{~cm}$ \\
Flow frame edge width (cm) & 5.0 & $\mathrm{~cm}$ \\
End plate material & $1+1$ & - \\
End plate thickness & & $\mathrm{cm}$ \\
\hline
\end{tabular}

The concentration and temperature variation of stack and tank of FAP450, VB2, F930 and Nafion 115 in the first day of operation are presented in Figure 5a-d. Taking FAP450 membrane (Figure 5a) as example, the concentration of $\mathrm{V}^{2+}$ and $\mathrm{VO}_{2}{ }^{+}$ions increase during charging while the $\mathrm{V}^{3+}$ and $\mathrm{VO}^{2+}$ ions decrease as expected. When the battery enters the standby mode and the pumps are switched off, the high SOC electrolyte inside the stack undergoes self-discharge reactions (1) and (4) so that the concentrations of $\mathrm{V}^{2+}$ and $\mathrm{VO}_{2}{ }^{+}$within the stack drops while $\mathrm{V}^{3+}$ and $\mathrm{VO}^{2+}$ ions increase. Due to the disparity of permeability rates of $\mathrm{V}^{2+}$ and $\mathrm{VO}_{2}{ }^{+}$ions across the FAP450 membrane, charged $\mathrm{V}^{2+}$ ions deplete faster than the $\mathrm{VO}_{2}{ }^{+}$ions. Since no self-discharge reactions occur in the tanks, the tank concentrations during the standby period remain constant until discharging starts. During the idle period, the self-discharge reactions in the stack are the only heat source, which can increase the temperature in the stack above $40{ }^{\circ} \mathrm{C}$. The consequence of such a temperature increase cannot be understated as $\mathrm{VO}_{2}{ }^{+}$tends to precipitate at temperature above $40{ }^{\circ} \mathrm{C}$ if the concentration is high, thereby increasing the risk of blockage in the cell stacks. However, in this case, the temperature increase is accompanied by a decrease in $\mathrm{VO}_{2}{ }^{+}$ion concentration in the stack, so no precipitation would be expected in the present situation. Furthermore, a drop in stack temperature can be achieved by turning on the pumps to allow the electrolyte to be circulated so as to dissipate the heat to the environment or into the tanks, as observed in the temperature profile in Figure 5a. Among all the 
membranes simulated here, Nafion 115 and F930 exhibit the largest heat generation and can even reach $50{ }^{\circ} \mathrm{C}$ while VB2 shows the best performance with the temperature only rising to around $28^{\circ} \mathrm{C}$. The peak temperature for the four membranes during the first cycle is in the order VB2 $<$ FAP450< F930 < Nafion 115.
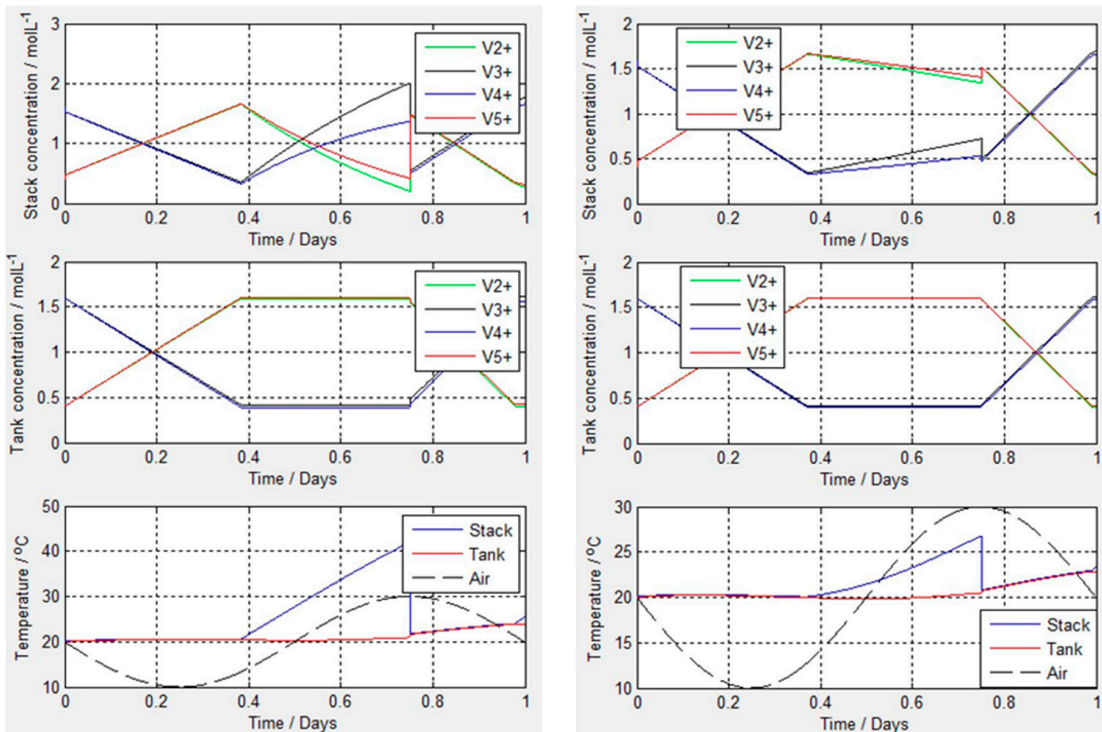

(a)

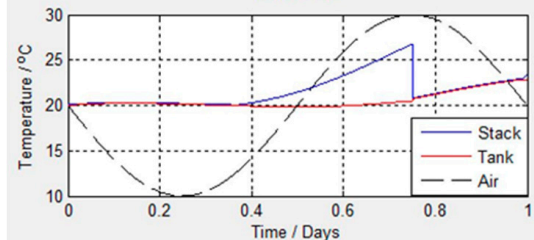

(b)
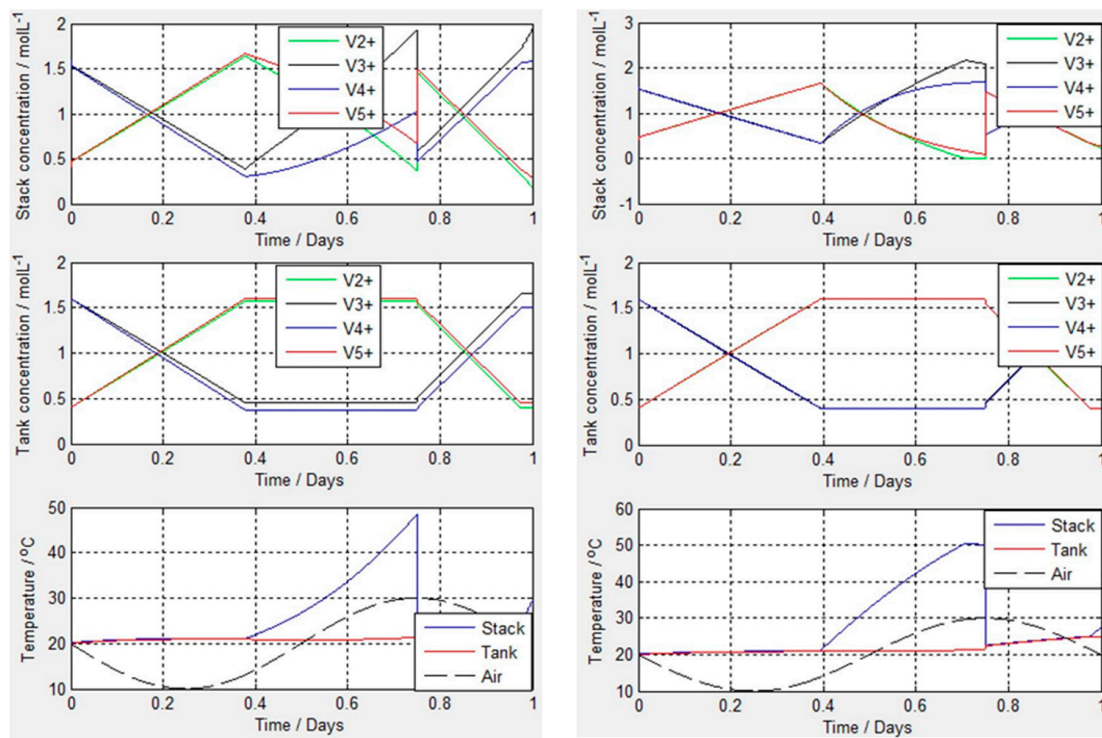

(c)

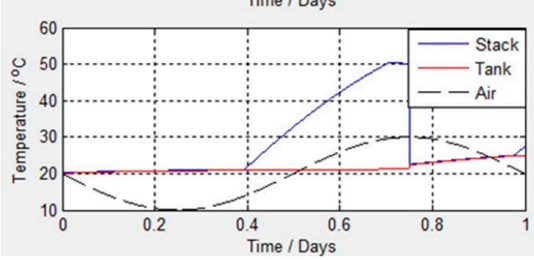

(d)

Figure 5. The simulated concentration and temperature variation of (a) FAP450; (b) VB2; (c) F930; and (d) Nafion 115 in the first day.

As the charged negative and positive electrolytes have the higher content of $\mathrm{V}^{2+}$ and $\mathrm{VO}_{2}{ }^{+}$ions respectively, the self-discharge reactions are mainly driven by the diffusion of these two ions. Therefore, Nafion 115, which has the higher values of $\mathrm{V}^{2+}$ and $\mathrm{VO}_{2}{ }^{+}$ion permeation rates, can contribute to more exothermic self-discharge reactions. Similar explanation can also be applicable in the VRFB with FAP450 membrane. Although F930 has relatively lower $\mathrm{V}^{2+}$ and $\mathrm{VO}_{2}{ }^{+}$diffusion coefficients, the smaller thickness of this membrane compared with the other materials gives rise to higher permeability rates and greater heat generation during the standby period. The VB2 membrane, being the thickest of the three commerical membranes inverstigated in this work, shows the lower degree of heat generation as expected. 
The trends of concentration and temperature in the stack and tank for the seven day period were also simulated and are illustrated in Figure 6. The growing imbalance between the SOC of two half-cells is attributed to the discrepancy among the permeability rates of the four vanadium ions. The decreasing capacity can be thus predicted by the model and regular rebalancing procedures can thus be taken. The stack temperature increases during the standby stage due to the considerable self-discharge reactions, but drops again once the pumps are turned on and fresh solution enters from the tanks. The tank temperature is seen to fluctate around $30^{\circ} \mathrm{C}$. VB2 still appears to be the one that produces the least heat during the stand-by period because of the smaller permeability values. Furthermore, the smaller variation in the diffusion coefficients of the four vanadium ions, also gives rise to the lowest imbalance between the ion concentrations in each half-cell. It can thus be infered that in order to avoid dramatic heat accumulation in the stack when the pumps are turned off during standby, the ideal membrane should possess low and balanced diffusion coefficients for all four vanadium ions or at least for the charged $\mathrm{V}^{2+}$ and $\mathrm{VO}_{2}{ }^{+}$ions.
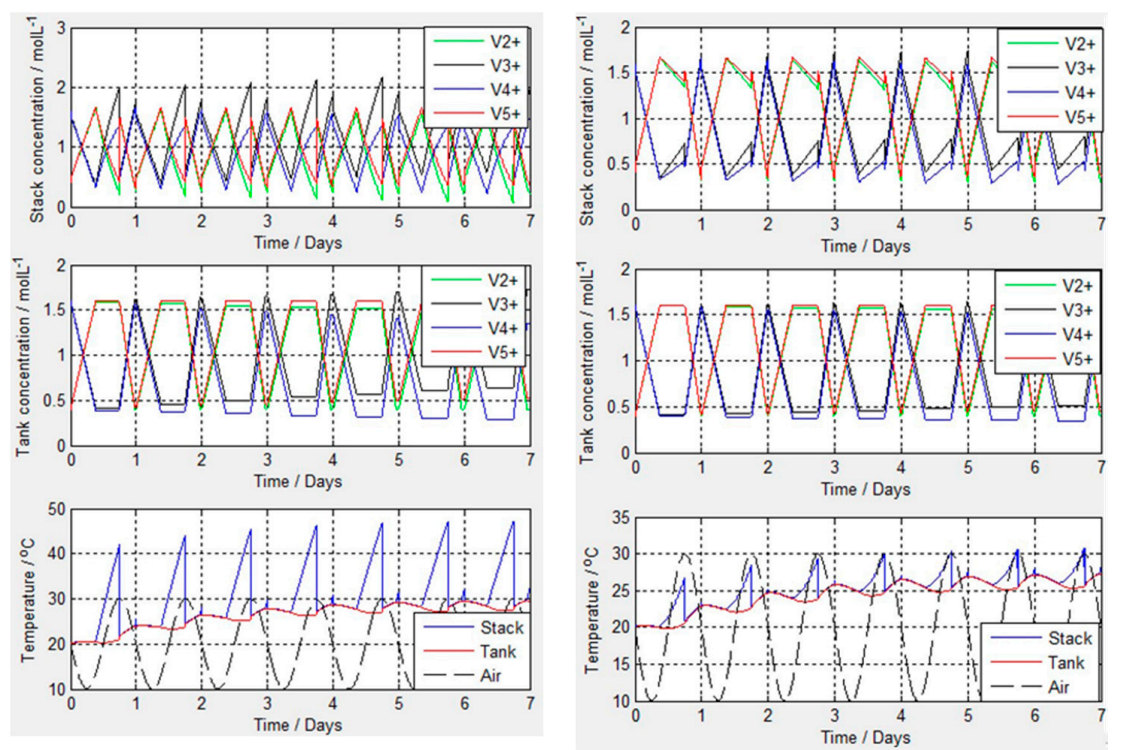

(a)

(b)
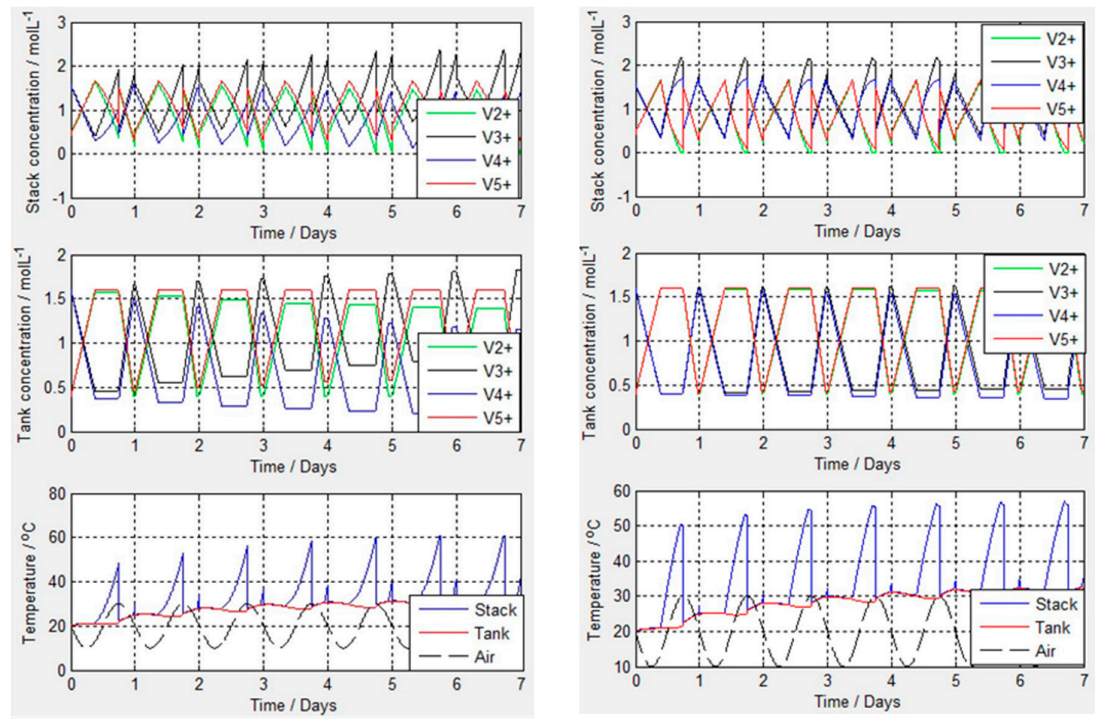

(c)

(d)

Figure 6. The simulated concentration and temperature variation of (a) FAP450; (b) VB2; (c) F930 and (d) Nafion 115 in a week. 
It should be pointed out however, that while small errors in the values of the calculated permeability rates will have only a minor effect on the predicted heat generation, the impact on the simulated concentration changes in each half-cell over time will be quite significant. The suggested capacity trends given in these simulations utilising the experimental permeability rates should therefore be treated with caution.

\section{Materials and Methods}

\subsection{Single Cell Setup}

The components of the single VRFB were fabricated in-house. Graphite felt of $6 \mathrm{~mm}$ thickness and a geometric area of $25 \mathrm{~cm}^{2}$ were employed on each side of the cell as anodes and cathodes. Three kinds of ion exchange membranes Fumasep ${ }^{\circledR}$ FAP-450, Fumasep ${ }^{\circledR}$ F930-rfd, (Fumatech, Bietigheim-Bissingen, Germany) and VB2 (V-Fuel, Sydney, Australia) were employed as the separators. Gaskets were used to adjust the compression of the electrodes to around $66.7 \%$ of the original thickness. Vanadium electrolyte (1.6 M vanadium in $4.2 \mathrm{M}$ sulphate solution) in each side of the reservoir was circulated through each half-cell by two MD-10-230GS01 Iwaki Magnet Pumps (Iwaki Pumps Australia, Sydney, Australia).

\subsection{Electrolyte Preparation}

$\mathrm{V}_{2} \mathrm{O}_{3}$ and $\mathrm{V}_{2} \mathrm{O}_{5}$ powders (EVRAZ Stratcor, Hot Springs, AR, USA) were dissolved in $\mathrm{H}_{2} \mathrm{SO}_{4}$ (Sigma-Aldrich, Sydney, Australia) to prepare the $\mathrm{VO}_{X} \mathrm{SO}_{4}$ solution. $\mathrm{V}^{2+}$ (violet) and $\mathrm{VO}_{2}{ }^{+}$(yellow) solutions were obtained by electrolysis and then mixed in a 1:2 and 2:1 volume ratio to prepare the $\mathrm{V}^{3+}$ and $\mathrm{VO}^{2+}$ electrolytes respectively. Milli-Q water (Merk Millipore, Melbourne, Australia) was used to dilute the electrolyte to the required concentrations. ICP-AES (Optima 7300 ICP-OES Spectrometers, PerkinElmer, Waltham, MA, USA) was utilized to determine the concentration of V in the solutions.

\subsection{Stability Test}

The stability tests were carried out by immersing the fresh membranes in $300 \mathrm{~mL} 1.6 \mathrm{~mol} \cdot \mathrm{L}^{-1}$ $\left(\mathrm{VO}_{2}\right)_{2} \mathrm{SO}_{4}$ in $2.6 \mathrm{~mol} \cdot \mathrm{L}^{-1} \mathrm{H}_{2} \mathrm{SO}_{4}$ solution at room temperature for more than 800 days. Periodically, the membranes were taken out and the electrolyte on the membrane surface was wiped with a tissue to remove surplus solution. Subsequently, the length, width and thickness were measured as indicators of the dimensional stability. The weight variation was also determined to evaluate the membrane stability in the highly oxidizing $\mathrm{VO}_{2}{ }^{+}$solution and to estimate electrolyte adsorption of the membranes.

\subsection{Diffusion Test}

The setup for the measurement of the permeability rate was designed as a cell with circulating vanadium electrolyte and blank solution of the same volume on each side of the membrane, as shown in Figure 7a. $70 \mathrm{~mL}$ vanadium solution and corresponding blank solution were filled in depletion and enrichment side respectively as described in Section 2.2 to equalize the ionic strength of the solutions and minimize osmotic pressure effects and solvent transfer. The chemicals used to prepare the blank solutions including $\mathrm{K}_{2} \mathrm{SO}_{4}, \mathrm{MgSO}_{4}$ and $\mathrm{Fe}_{2}\left(\mathrm{SO}_{4}\right)_{3}$ were purchased from Sigma-Aldrich, Sydney, Australia. Inert gas protection was provided during the permeability measurements for $\mathrm{V}^{2+}$ ions. The reservoirs were shielded from the light when using $\mathrm{Fe}^{3+}$ in the test cell to avoid photodecomposition of $\mathrm{Fe}_{2}\left(\mathrm{SO}_{4}\right)_{3}$. The solutions on both sides were pumped through the diffusion cell in order to avoid concentration polarization at the membrane surface, as shown in Figure $7 \mathrm{~b}, \mathrm{c}$, respectively. At regular intervals, $1 \mathrm{~mL}$ samples were withdrawn from the blank solution and measured by ICP-AES to determine the concentration of the vanadium ions within an accuracy of $99 \%$. The temperature of the solution in the enrichment reservoir was monitored during the entire diffusion test. For each diffusion test, a new and dry membrane was used as received. 


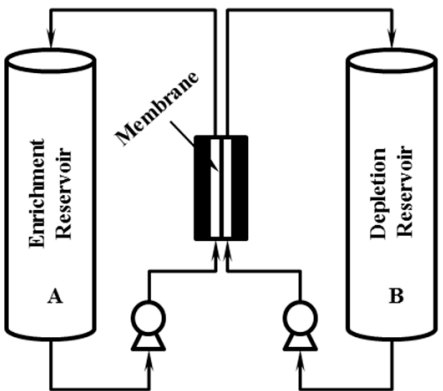

(a)

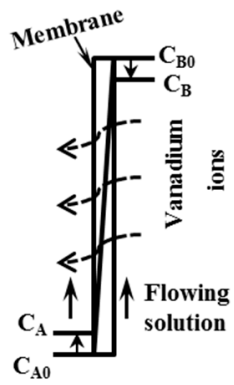

(b)

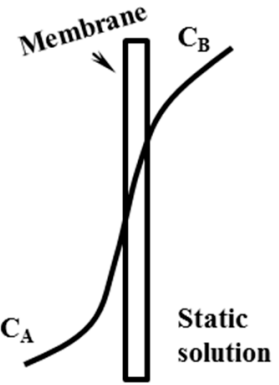

(c)

Figure 7. (a) Apparatus for determination of permeability and the concentration gradient; (b) without and (c) with diffusion layer on the surface of membrane.

\subsection{Cycling Test}

Charge and discharge curves were performed by a RePower Battery Test System (RePower, Shenzhen, China) within the voltage range of $1.0 \mathrm{~V}$ and $1.65 \mathrm{~V}$ at a constant current density of $40 \mathrm{~mA} \cdot \mathrm{cm}^{-2}$. The voltage range is set to minimize the influence of gassing side reactions. However, $\mathrm{H}_{2}$ evolution was observed in the negative half-cell at the end of the charging cycle. Parafilm ${ }^{\circledR} \mathrm{M}$ (Sigma-Aldrich, Sydney, Australia) was also placed on top of the reservoir to minimize water evaporation and air oxidation of the anolyte. Coulombic efficiency (CE), voltage efficiency (VE) and energy efficiency (EE) values were calculated based on the following equations:

$$
\begin{gathered}
\mathrm{CE}(\%)=(\text { Discharge capacity }) /(\text { Charge capacity }) \times 100 \% \\
\mathrm{EE}(\%)=(\text { Discharge energy }) /(\text { Charge energy }) \times 100 \% \\
\operatorname{VE~}(\%)=\mathrm{EE} / \mathrm{CE} \times 100 \%
\end{gathered}
$$

\subsection{Model Development}

The thermal model according to energy balance to simulate the electrolyte temperature in the stack and tank can be found in [1]. Any parameters different from the references are specified in the previous sections.

\section{Conclusions}

A modified methodology was developed in this study for the determination of vanadium ion diffusion coefficients for three different membranes currently being used or considered for VRB applications. The anion exchange membrane FAP450, showed a similar order of magnitude of permeability rates for all four vanadium ions, while in the case of the cation exchange membranes F930 and VB2 the permeability of $\mathrm{V}^{2+}$ and $\mathrm{VO}_{2}{ }^{+}$ions was almost an order of magnitude lower than that of $\mathrm{V}^{3+}$ and $\mathrm{VO}^{2+}$. Of the two cation exchange membranes, the thicker VRB exhibited the lowest permeability values as would be expected. The experimental data was applied in simulation studies to investigate the effect of ion crossover on thermal behavior associated with self-discharge reactions caused by ion diffusion across the membrane. In order to reduce the stack temperature rise when pumps are switched off during standby periods at high SOCs, lower order of magnitudes of the permeability rates of $\mathrm{V}^{2+}$ and $\mathrm{VO}_{2}{ }^{+}$ions are essential. This requirement was satisfied by the thicker VB2 membrane in the present study.

Acknowledgments: The authors thank Faculty of Engineering, UNSW for the financial support; Rabeya Akter and Dorothy Yu from Mark Wainwright Analytical Centre UNSW for ICP analysis. Liuyue Cao has been supported by University International Postgraduate Award Scholarship. 
Author Contributions: Liuyue Cao, Da-Wei Wang and Maria Skyllas-Kazacos conceived and designed the experiments; Liuyue Cao performed permeability measurement, cycling test and did the dynamic cycling simulation; Ander Kronanders tested the cell efficiencies of FAP450 membrane; Ao Tang contributed the thermal model; Maria Skyllas-Kazacos carried out the thermal simulations; Liuyue Cao and Maria Skyllas-Kazacos analyzed the data and wrote the paper.

Conflicts of Interest: The authors declare no conflict of interest. The founding sponsors had no role in the design of the study; in the collection, analyses, or interpretation of data; in the writing of the manuscript, and in the decision to publish the results.

\section{References}

1. Tang, A.; Bao, J.; Skyllas-Kazacos, M. Thermal modelling of battery configuration and self-discharge reactions in vanadium redox flow battery. J. Power Sources 2012, 216, 489-501. [CrossRef]

2. Tang, A.; Ting, S.; Bao, J.; Skyllas-Kazacos, M. Thermal modelling and simulation of the all-vanadium redox flow battery. J. Power Sources 2012, 203, 165-176. [CrossRef]

3. Mohammadi, T.; Skyllas-Kazacos, M. Preparation of sulfonated composite membrane for vanadium redox flow battery applications. J. Membr. Sci. 1995, 107, 35-45. [CrossRef]

4. Xi, J.; Wu, Z.; Teng, X.; Zhao, Y.; Chen, L.; Qiu, X. Self-assembled polyelectrolyte multilayer modified Nafion membrane with suppressed vanadium ion crossover for vanadium redox flow batteries. J. Mater. Chem. 2008, 18, 1232-1238. [CrossRef]

5. Teng, X.; Zhao, Y.; Xi, J.; Wu, Z.; Qiu, X.; Chen, L. Nafion/organically modified silicate hybrids membrane for vanadium redox flow battery. J. Power Sources 2009, 189, 1240-1246. [CrossRef]

6. Chen, D.; Wang, S.; Xiao, M.; Meng, Y. Preparation and properties of sulfonated poly(fluorenyl ether ketone) membrane for vanadium redox flow battery application. J. Power Sources 2010, 195, 2089-2095. [CrossRef]

7. Mai, Z.; Zhang, H.; Zhang, H.; Xu, W.; Wei, W.; Na, H.; Li, X. Anion-conductive membranes with ultralow vanadium permeability and excellent performance in vanadium flow batteries. ChemSusChem 2013, 6, 328-335. [CrossRef] [PubMed]

8. Luo, Q.; Zhang, H.; Chen, J.; Qian, P.; Zhai, Y. Modification of Nafion membrane using interfacial polymerization for vanadium redox flow battery applications. J. Membr. Sci. 2008, 311, 98-103. [CrossRef]

9. Luo, Q.; Zhang, H.; Chen, J.; You, D.; Sun, C.; Zhang, Y. Preparation and characterization of Nafion/SPEEK layered composite membrane and its application in vanadium redox flow battery. J. Membr. Sci. 2008, 325, 553-558. [CrossRef]

10. Wang, Y.; Wang, S.; Xiao, M.; Han, D.; Hickner, M.A.; Meng, Y. Layer-by-layer self-assembly of PDDA/PSS-SPFEK composite membrane with low vanadium permeability for vanadium redox flow battery. RSC Adv. 2013, 3, 15467-15474. [CrossRef]

11. Jia, C.; Liu, J.; Yan, C. A significantly improved membrane for vanadium redox flow battery. J. Power Sources 2010, 195, 4380-4383. [CrossRef]

12. Grossmith, F.; Llewellyn, P.; Fane, A.G.; Skyllas-Kazacos, M. Evalution of membranes for all-vanadium redox cell. In Stationary Energy Storage, Load Levelling, and Remote Applications; Publisher: Honolulu, HI, USA, 1988; pp. 363-374.

13. Wiedemann, E.; Heintz, A.; Lichtenthaler, R.N. Transport properties of vanadium ions in cation exchange membranes: Determination of diffusion coefficients using a dialysis cell. J. Membr. Sci. 1998, 141, $215-221$. [CrossRef]

14. Sun, C.; Chen, J.; Zhang, H.; Han, X.; Luo, Q. Investigations on transfer of water and vanadium ions across Nafion membrane in an operating vanadium redox flow battery. J. Power Sources 2010, 195, 890-897. [CrossRef]

15. Leung, P.K.; Xu, Q.; Zhao, T.S.; Zeng, L.; Zhang, C. Preparation of silica nanocomposite anion-exchange membranes with low vanadium-ion crossover for vanadium redox flow batteries. Electrochim. Acta 2013, 105, 584-592. [CrossRef]

16. Tanaka, Y. Fundamental Properties of Ion Exchange Membranes, 2nd ed.; Elsevier Science: Amsterdam, The Netherlands, 2015.

17. Fick, A. Ueber Diffusion. Ann. Phys. 1855, 170, 59-86. [CrossRef]

18. Arrhenius, S. Über die Dissociationswärme und den Einflusß der Temperatur auf den Dissociationsgrad der Elektrolyte; Wilhelm Engelmann: Leipzig, Germany, 1989. (In German) 
19. Luo, X.; Lu, Z.; Xi, J.; Wu, Z.; Zhu, W.; Chen, L.; Qiu, X. Influences of permeation of vanadium ions through PVDF-g-PSSA membranes on performances of vanadium redox flow batteries. J. Phys. Chem. B 2005, 109, 20310-20314. [CrossRef] [PubMed]

20. Qiu, J.; Zhao, L.; Zhai, M.; Ni, J.; Zhou, H.; Peng, J.; Li, J.; Wei, G. Pre-irradiation grafting of styrene and maleic anhydride onto PVDF membrane and subsequent sulfonation for application in vanadium redox batteries. J. Power Sources 2008, 177, 617-623. [CrossRef]

21. Xi, J.; Wu, Z.; Qiu, X.; Chen, L. Nafion $/ \mathrm{SiO}_{2}$ hybrid membrane for vanadium redox flow battery. J. Power Sources 2007, 166, 531-536. [CrossRef]

22. Heintz, A.; Wiedemann, E.; Ziegler, J. Ion exchange diffusion in electromembranes and its description using the Maxwell-Stefan formalism. J. Membr. Sci. 1997, 137, 121-132. [CrossRef]

23. Chen, J.; Wang, B.; Yang, J. Adsorption and Diffusion of $\mathrm{VO}^{2+}$ and $\mathrm{VO}_{2}{ }^{+}$across Cation Membrane for All-Vanadium Redox Flow Battery. Solvent Extr. Ion Exch. 2009, 27, 312-327. [CrossRef]

24. Wiedemann, E.; Heintz, A.; Lichtenthaler, R.N. Sorption isotherms of vanadium with $\mathrm{H}_{3} \mathrm{O}^{+}$ions in cation exchange membranes. J. Membr. Sci. 1998, 141, 207-213. [CrossRef]

25. Vijayakumar, M.; Bhuvaneswari, M.S.; Nachimuthu, P.; Schwenzer, B.; Kim, S.; Yang, Z.; Liu, J.; Graff, G.L.; Thevuthasan, S.; Hu, J. Spectroscopic investigations of the fouling process on Nafion membranes in vanadium redox flow batteries. J. Membr. Sci. 2011, 366, 325-334. [CrossRef]

26. Cui, S.; Paddison, S.J. A molecular dynamics study of the effects of $\mathrm{V}^{2+}$ and $\mathrm{V}^{3+}$ on the local structure of hydrated Nafion. J. Phys. Chem. C 2015, 119, 12848-12855. [CrossRef]

27. Mohammadi, T.; Skyllas-Kazacos, M. Evaluation of the chemical stability of some membranes in vanadium solution. J. Appl. Electrochem. 1997, 27, 153-160. [CrossRef]

28. Gildemeister. (Würzburg, Germany). Private communication, 2014.

29. Qiu, J.; Li, M.; Ni, J.; Zhai, M.; Peng, J.; Xu, L.; Zhou, H.; Li, J.; Wei, G. Preparation of ETFE-based anion exchange membrane to reduce permeability of vanadium ions in vanadium redox battery. J. Membr. Sci. 2007, 297, 174-180. [CrossRef]

30. Lin, C.-H.; Yang, M.-C.; Wei, H.-J. Amino-silica modified Nafion membrane for vanadium redox flow battery. J. Power Sources 2015, 282, 562-571. [CrossRef]

31. Donnan, F.G. Die genaue thermodynamik der membranegleichgewichte. Z. Phys. Chem. A 1934, 168, 369-380. (In German)

32. Sepehr, F.; Paddison, S.J. Effect of sulfuric and triflic acids on the hydration of vanadium cations: An ab initio study. J. Phys. Chem. A 2015, 119, 5749-5761. [CrossRef] [PubMed]

33. Strehlow, H.; Wendt, H. Fast ionic reactions in solution. IV. The formation of the vanadyl sulfate complex in aqueous solution. Inorg. Chem. 1963, 2, 6-10. [CrossRef]

34. Yamamoto, H. Mobility of counter ion in ion exchange membrane. Bull. Soc. Sea Water Sci. Japan 1968, 22, 323-326.

35. Morgan, R.A.; Sloan, W.H. Extrusion Finishing of Perfluorinated Copolymers. U.S. Patent 4,626,587A, 2 December 2012.

36. Smith, R.A.; Withers, M.S. Coextruded Multilayer Cation Exchange Membranes. U.S. Patent 4, 437,952A, 20 March 1984.

37. Curtin, D.E.; Lousenberg, R.D.; Henry, T.J.; Tangeman, P.C.; Tisack, M.E. Advanced materials for improved PEMFC performance and life. J. Power Sources 2004, 131, 41-48. [CrossRef]

(C) 2016 by the authors; licensee MDPI, Basel, Switzerland. This article is an open access article distributed under the terms and conditions of the Creative Commons Attribution (CC-BY) license (http://creativecommons.org/licenses/by/4.0/). 